\title{
Hacer investigación en la sociabilidad nocturna: una reflexión metodológica sobre los proyectos migratorios de las mujeres trans y travestis sudamericanas en el AMBA
}

\author{
RAMIRO NICOLAS PEREZ RIPOSSIO \\ Universidad de Buenos Aires | Buenos Aires, Argentina \\ pramiro907@gmail.com
}

DOI 10.11606/issn.2316-9133.v30i1pe180761

resumen En este artículo presento una reflexión metodológica sobre la práctica investigativa en espacios de sociabilidad nocturna (discotecas y bares) sobre un estudio acerca de los proyectos migratorios de las travestis/trans sudamericanas que residieron en el AMBA durante los años 2017-2019, teniendo en cuenta algunas características de estos itinerarios. Aquí, me preguntó por los modos de proceder en la noche dado los desafíos éticos que supone. La tradición etnográfica que ha investigado a la población travesti/trans desde la década de 1990 se ha preocupado por las maneras en que los/as investigadores acceden a campo teniendo en cuenta que la reflexividad, la posicionalidad y la subjetividad del etnógrafo resultan fundamentales. En particular, el lugar del cuerpo sexuado del investigador/a ha adquirido relevancia central en las preocupaciones antropológicas debido a que se considera que posee múltiples implicancias en el trabajo investigativo. De acuerdo con los procedimientos aplicados describo las performances llevadas a cabo en la noche, es decir, en la sociabilidad nocturna, prestándole atención a los desafíos teóricos metodológicos.

palabras clave Travestis y transgeneridad. Migraciones. Sociabilidad nocturna. Metodología cualitativa

Researching the nocturnal sociability: a methodological reflection on the migratory projects of South American travestis and trans women at Buenos Aires

abstract The article presents a methodological reflection on the investigative practice in spaces of nocturnal sociability (disco clubs and bars) during a study about the migratory projects of South American transvestites / trans women who resided in the metropolitan area of Buenos Aires between 2017-2019. It focuses on the ways the researcher proceeds at night given the ethical challenges it poses. The ethnographic tradition that has 
investigated the transvestite / trans population since the 1990s has been concerned with the ways in which researchers enter the field, considering that the reflexivity, positionality and subjectivity of the ethnographer are fundamental. In particular, the place of the sexed body of the researcher has acquired central relevance in anthropological concerns because it is considered to have multiple implications in research work. In accordance with the procedures applied, I describe the performances carried out at night, that is, in the nocturnal sociability, paying attention to the theoretical and methodological challenges.

keywords Travestis and trans women. Migrations. Nocturnal sociability. Qualitative methodology

\section{Pesquisando a sociabilidade noturna: uma reflexão metodológica sobre os projetos migratórios de mulheres trans e travestis em Buenos Aires}

resumo Neste artigo apresento uma reflexão metodológica sobre a prática investigativa em espaços de convivência noturna (discotecas e bares) sobre um estudo sobre os projetos migratórios de travestis / trans sul-americanos que residiram na AMBA durante os anos 2017-2019, levando em consideração algumas características desses itinerários. Aqui, questiono as maneiras de proceder à noite, dados os desafios éticos que ela apresenta. A tradição etnográfica que investiga a população travesti / trans desde a década de 1990 tem se preocupado com as formas de inserção dos pesquisadores no campo, levando em consideração que a reflexividade, a posicionalidade e a subjetividade do etnógrafo são fundamentais. Em particular, o lugar do corpo sexuado do pesquisador adquiriu relevância central nas preocupações antropológicas por ser considerado como tendo múltiplas implicações no trabalho de pesquisa. De acordo com os procedimentos aplicados, descrevo as performances realizadas no período noturno, ou seja, na sociabilidade noturna, atento aos desafios teóricos e metodológicos.

palavras-chave Travestilidade e transgeneridade Migrações. Sociabilidade noturna. Metodologia qualitativa

\section{Introducción ${ }^{1}$}

En este artículo propongo una reflexión teórico-metodológica respecto de los modos de hacer y proceder durante el trabajo de campo en una investigación sobre el proceso migratorio de las travestis y mujeres trans ${ }^{2}$ sudamericanas que residen en el AMBA (Área Metropolitana de Buenos Aires) ${ }^{3}$, durante los años 2017-2019.

\footnotetext{
${ }^{1}$ El artículo forma parte de una tesis doctoral ya concluida en la Universidad de Buenos Aires.

${ }^{2}$ Para los fines de este artículo "travestis y mujeres trans" y "travestis/trans" se emplean en el mismo sentido. Se trata de procesos de construcción de identidad complejos que bajo el prefijo "trans" quedan englobadas. "Travesti” es un término de relevancia política en Latinoamérica.

${ }^{3}$ El AMBA comprende, en esta investigación, a la CABA (Ciudad Autónoma de Buenos Aires) y del conurbano bonaerense algunos partidos como Esteban Echeverría y Morón. En algunos casos, las unidades de análisis residen en CABA, pero poseen trayectorias biográficas en las que han transitado por partidos como Quilmes y
} 
La migración es uno de los elementos más comunes en las trayectorias biográficas de las personas travestis y trans. Sin embargo, ha sido uno de los aspectos menos investigados en la República Argentina tanto por los estudios migratorios como por los estudios de género. En Brasil, por ejemplo, diferentes investigaciones (Vale 2005; Vartabedian 2012; Guerra 2020, entre otras) se preocuparon en comprender la manera en que los itinerarios geográficos y corporales se entrecruzan, es decir, observaron como la migración posibilita e impulsa procesos de construcción corporal en tanto baluartes de la identidad de género. Se trata de personas travestis/trans que se han desplazado hacia diferentes países de Europa en donde también experimentan mayores libertades e incrementan sus recursos económicos.

Otras investigaciones (Cerezo et al 2014; Padilla et al. 2016) han observado la migración centroamericana hacia Estados Unidos atendiendo los motivos de la migración y la discriminación institucionalizada una vez que consolidan sus biografías. Aquí no se agotan las diferentes investigaciones sobre el tema que permiten aseverar que en los últimos veinte años se ha constituido un campo de estudios que vincula la migración con la identidad de género de las personas travestis/trans. De todas maneras, dicho campo es aún emergente y más aún si acotamos las producciones elaboradas en la República Argentina.

Las travestis/trans sudamericanas experimentan, en sus sociedades de origen, diferentes discriminaciones, vulnerabilidades, violencias y criminalizaciones que las impulsan a migrar en búsqueda de escenarios de menor hostilidad (Berkins 2003). No obstante, cuando se insertan en la sociedad receptora (Argentina), estos factores se modifican y emergen otros, como resultado de una matriz de dominación que articula diferentes sistemas de opresión (condición étnica nacional, identidad de género y clase social) (Hill Collins 1990). De todas maneras, la migración representa la posibilidad de expresarse en contextos culturales de mayor comprensión, incrementar recursos económicos y acceder a derechos. Las travestis y mujeres trans sudamericanas se valen de un conjunto de cadenas migratorias necesarias para efectuar el desplazamiento y asimilarse en la sociedad receptora. Estas personas, luego de consolidar un proyecto de vida en el AMBA, llevan a cabo experiencias de regreso a sus entornos logrando mayores niveles de aceptación social. La investigación realizada ha podido comprobar que la migración si bien no se encuentra exenta de tensiones, representa una estrategia de inversión económica y simbólica que permite mejorar la posición en el espacio social y acceder a derechos esenciales.

Por otra parte, esta investigación doctoral fue realizada en espacios de sociabilidad nocturna gayfriendly implicando una serie de desafíos ético prácticos vinculados con la práctica investigativa. Con base en Blázquez y Liarte Tiloca (2018), la noche puede constituirse como un espacio etnográfico en donde el cuerpo del investigador queda inmerso y a la deriva en un conjunto de interacciones y sociabilidades. Las prácticas llevadas a cabo por los etnógrafos/as en el campo se encuentran inmersas en un conjunto de interacciones

Florencio Varela. Es pertinente establecer que el AMBA incluye la CABA y cuarenta municipios de la provincia de Buenos Aires. 
que suponen diferentes desafíos, entre ellos, construir investigaciones validas, confiables y con sustento ético.

Esta investigación utilizó una combinación entre el método etnográfico y algunos aspectos de la teoría fundamentada (Strauss y Corbin 2002) con el fin de desarrollar categorías emergentes robustas. Las técnicas de investigación fueron la entrevista en la modalidad de los relatos de vida y la observación participante. Si bien la sociabilidad nocturna no fue el espacio exclusivo en donde se desarrolló el trabajo de campo, la mayoría de las entrevistas y observaciones provinieron de casos encontrados en esos ámbitos. La muestra quedó integrada, finalmente, por 44 casos, de los cuales 3 fueron informantes clave (dos travestis/trans nativas y una mujer cisgénero). El resto se trató de 41 migrantes travestis/trans sudamericanas con diferentes características sociodemográficas. Además, se tuvo contacto con alrededor de 130 travestis/trans entre las nativas y las sudamericanas que involucró tanto a las entrevistadas como aquellas con las que se generaron conversaciones en el contexto de la observación participante.

La noche como espacio en el que se desarrolla la práctica de investigación supone múltiples desafíos y puede ocasionar diferentes controversias éticas. De este modo, se plantean responder los siguientes interrogantes: ¿Cómo se delinean los límites del trabajo etnográfico? ¿Cuáles son las tensiones existentes en relación con el cuerpo sexuado del investigador en el campo? ¿Qué estrategias pueden desplegarse para acceder a la información que se requiere manteniendo el rol de investigador/a?

El artículo presenta cuatro secciones. Primero, define qué entiende por trabajo de campo, luego presenta los obstáculos de acceso iniciales que se presentaron en la investigación, también describe las diferentes tensiones que se produjeron en el contexto de la sociabilidad nocturna y que refieren a la dimensión del cuerpo sexuado del investigador al realizar esta tarea. Finalmente describe algunos procedimientos llevados a cabo en el barrio de Constitución de la Ciudad Autónoma de Buenos Aires en donde las travestis/trans sudamericanas ejercen la prostitución y entablan sociabilidades de diversa índole.

\section{El trabajo de campo}

Como punto de partida, es oportuno determinar que para esta investigación el conocimiento se produce de manera situada (Haraway 1995). De este modo, no asumo una postura asociada a la ingenuidad propia de la neutralidad valorativa; por el contrario, busco describir el trabajo de campo de una investigación que ha considerado a las unidades de análisis en tanto agentes activos, observando los efectos provocados por mi presencia en el campo, siendo reflexivo sobre ellos y entendiendo también la capacidad de los propios agentes para modificar las prenociones propias e incluso desestabilizarlas.

El trabajo de campo de esta investigación doctoral se realizó entre mediados del 2017 y mediados del 2019. Sus principales características fueron la utilización y la superposición de diversos métodos y técnicas complementarias, y las características multisituadas de los escenarios en donde se llevó a cabo. Con base en Guber (2004): 
El campo de una investigación es su referente empírico, la porción de lo real que se desea conocer, el mundo natural y social en el cual se desenvuelven los grupos humanos que lo construyen. Se compone, en principio, de todo aquello con lo que se relaciona el investigador, pues el campo es una cierta conjunción entre un ámbito físico, actores y actividades (Guber 2004: 47).

El trabajo de campo representa un momento bisagra en la investigación cuyas condiciones de posibilidad se encuentran condicionadas por una serie de factores. En suma, en esas condiciones es que la habilidad y experiencia de los investigadores cobra importancia para que esta tarea pueda concluir de manera favorable. Por eso, Flores et al. (1999) sostienen que el acceso a campo representa uno de los momentos más difíciles de la investigación cualitativa. Por lo general, se trata de sortear una serie de dificultades y obstáculos que son el resultado de factores objetivos, externos al investigador, y aspectos subjetivos vinculados con los propios atributos que impactan en la realización del trabajo de campo.

El esfuerzo etnográfico realizado en esta investigación implicó emplear una multiplicidad de recursos con el fin de construir un material empírico abundante y de relevancia teórica. Además, se elaboró una matriz que permitió establecer los tópicos de mayor relevancia para la investigación, organizar el trabajo de campo y diseñar una guía de pautas inicial que se fue refinando a lo largo del proceso. Como sostienen Hernández Sampieri et al. (2010), estas intervenciones posibilitaron no caer en improvisaciones, que se trata de uno de los principales factores cuando se pretende alcanzar la validez del estudio cualitativo.

A continuación, presento diferentes fases del trabajo de campo. En primer lugar, se exponen las dificultades de acceso y luego se caracterizan los diferentes espacios en lo que se realizó la investigación teniendo en cuenta los obstáculos y las tensiones del "estar allí".

\section{Avatares del campo}

Con fundamento en Taylor y Bogdan (1987), durante los primeros días en el campo, los investigadores perciben incomodidad y falta de adaptación al contexto, puesto que la entrada a este suele ser una de las instancias más delicadas. El poder acceder a las personas estudiadas implica interrogarse sobre dónde encontrarlos y cómo dirigirse a ellos asumiendo distintos papeles que, desde el comienzo, atraviesan la figura del extraño, la del visitante y la del iniciado hasta ser considerado un miembro del grupo (Flick 2007).

En este apartado, recupero la primera persona del singular para relatar la experiencia de campo desde un "yo testifical". Antes de iniciar esta tarea, consideré como principal opción entrevistar a migrantes travestis/trans sudamericanas que estuvieran nucleadas en organizaciones políticas. De acuerdo con lo que había leído en numerosas investigaciones, al parecer, esta manera de proceder representaba la alternativa más fiable. La estrategia que 
desarrollé implicó, en primer lugar, enviar mails a distintas organizaciones indicándoles mi procedencia institucional con la intención de realizar entrevistas anónimas e individuales enmarcadas en una tesis doctoral.

En esta instancia pude percibir que las organizaciones poseen algún tipo de protocolo específico para los académicos que intentan acceder de este modo. En algunos casos, solicitan el envío de un correo electrónico con información detallada; en otros, piden algún teléfono o correo electrónico para luego comunicarse por medio de algún representante institucional. Las organizaciones políticas prometían comunicarse en el futuro, algo que, en la mayoría de los casos, no se concretó. Es probable que existiera desconfianza de parte de estas organizaciones sabiendo que, de algún modo, investigar a sus miembros implicaba también referirse a sus estructuras. Respecto de la escasa magnitud que pueda atribuírsele al fenómeno de estudio (Stang 2013), considero que las migraciones de las travestis/trans sudamericanas hacia el AMBA representan un hecho social desde hace al menos dos décadas y muchas de estas organizaciones se nutren de esta población. Por eso, la falta o ausencia de personas migrantes travestis/trans sudamericanas en organizaciones políticas o en cualquier otro ámbito no representaba un argumento fiable.

En esta instancia del trabajo de campo, tenía en claro que las organizaciones políticas de personas travestis/trans no representaban una opción de fácil acceso. Esta situación pudo ser consecuencia de numerosos aspectos que se vinculan con las dinámicas internas de las propias organizaciones. Además, las características subjetivas del propio investigador influyeron en las condiciones de acceso. Soy un varón cisgénero, heterosexual, normativo, hegemónico y con un capital social nulo dentro del LGTBIQ+, por lo que generar empatía con estas personas y mediantes estas instituciones no resultaría una tarea sencilla. Esto pudo ser constatado, ya que otros colegas, en su mayoría mujeres cisgénero, pudieron acceder a las mismas organizaciones con relativa facilidad. Asimismo, algunas de ellas no contaban con contactos previos y aplicaron procedimientos similares a los elaborados por esta investigación.

En suma, teniendo en cuenta el proceso relacional y encarnado de producción de la experiencia etnográfica, debe destacarse una cierta ambigüedad en la producción de la experiencia de campo. Por un lado, mi participación fue limitada como varón cisgénero, heterosexual, atravesado por privilegios dentro del sistema social argentino y con escaso capital social respecto al universo LGTBIQ+. Sin embargo, mi participación fue posible gracias al proceso de construcción de relaciones de amistad y también a la dinámica de deseos que construyó mi presencia en el campo. Por ello, aunque mi intervención fue diferente en comparación con otros investigadores con procedimientos similares, ofrece algunos elementos interesantes para la reflexión. En esta instancia, reflexioné sobre otras posibilidades para poder acceder al campo. La segunda estrategia es presentada a continuación y constituye el núcleo central del artículo. 


\section{Los venues}

$\mathrm{Ni}$ las organizaciones políticas ni los espacios en los que se ejerce la prostitución, los venues representaron la primera aproximación viable de acceso al campo. Los venues suelen ser denominados como boliches o discotecas, pero la designación aquí empleada representa un concepto de mayor importancia. Es la forma de nombrar espacios de encuentro en el que prima un conjunto de interacciones destinadas a la seducción (Rieznik y Tabschek 2013), aunque puede constituirse relaciones sociales de diversos tipos. El venue es el espacio en donde se constituyen diversas performances de seducción que dan lugar a interacciones cuyos fines son, por lo general, afectivos. La noche ha sido investigada como un espacio en el que se gestan diversas relaciones sociales y se performan determinadas normas de género atravesadas por la clase social y la etnicidad (Blázquez 2012; Bianciotti 2015; Perez Ripossio 2020).

Por otra parte, yo poseía conocimiento de que en algunos espacios específicos asistían travestis/trans y la información que circulaba en internet lo corroboraba. Los primeros resultados de las búsquedas realizadas mencionaban y describían aspectos de la discoteca Amerik. Los comentarios en la web indicaban que era un lugar "lleno de travas". Pude leer comentarios descalificadores hacia el público que asistía a Amerik y se hacía hincapié en la fuerte presencia de migrantes sudamericanos/as. Por eso, podía representar un lugar propicio para hacer un primer acercamiento y generar los primeros contactos.

Esta alternativa de acceso no se trataba de una forma de proceder novedosa. Autores como, por ejemplo, Perlongher (1993), Braz (2010) y Liarte Tiloca (2019) habían aplicado procedimientos similares. La diferencia de mi investigación, en relación con la de estos antropólogos, radicaba en que el objeto de estudio no podía observarse de manera directa en esos espacios porque mi interés no se orientaba a describir las interacciones que se producían en las discotecas de ambiente gay. En todo caso, estos espacios podrían representar una fuente de capital social necesario para poder realizar entrevistas a posteriori. Y esto suponía entrar en contacto con personas desconocidas y en un contexto en el que carecía de total experiencia.

Lo cierto es que la mejor opción para comenzar con esta estrategia era la discoteca Amerik. Este espacio, ubicado en el barrio de Villa Crespo, es un clásico de la noche del colectivo LGTBIQ+. Posee una entrada a un precio común, que permite acceder a una barra libre. Además, es conocido por su dark room o "el túnel”, espacios típicos en los boliches gays, reservados para el ejercicio de prácticas sexuales. En Amerik, pude observar un importante número de trans/travestis e intuía que algunas podían ser migrantes. La mayoría de ellas suele nuclearse en un entrepiso del venue, en donde hay una barra con mesas y sillas, y un baño mixto con piletas comunes que funciona como un sector para fumadores.

Es pertinente problematizar el modo en que se produce la entrada al campo. En este caso, luego de asistir durante un tiempo a Amerik, la decisión se orientaba a comenzar a interactuar con algunas travestis/trans sudamericanas. En el espacio en el que suelen reunirse ellas, pude observar que mi subjetividad era objeto de observación, lo que me 
generaba cierta tensión que oscilaba entre sentimientos de comodidad e incomodidad. Vartabedian (2012) pudo constatar conductas similares en su trabajo de campo afirmando que las migrantes travestis/trans observaban y comentaban aspectos de su corporalidad. En mi caso, ocurría algo similar, miradas incisivas y gestos corporales que permitían deducir que estaba en condiciones de entablar conversaciones, pero, al mismo tiempo, las características contextuales y las necesidades de la investigación parecían no complementarse. Las miradas de deseo que recaían sobre mí tensionaban la labor a realizar porque si bien era necesario representar una performatividad acorde con el espacio, también debía aclarar mi posición en este lugar.

Una de esas noches, pude observar y escuchar que una travesti/trans hablaba casi gritando mientras caminaba con dos varones. Uno de ellos parecía ser un amigo gay; el otro era un muchacho interesado en ella. Este joven la detuvo y se dirigía a ella con una insistencia intensa. Mientras tanto, podía ver cómo se le acercaba más y más, tirándosele encima en más de una oportunidad. Notaba también que ella quería sacárselo de encima. Intentaba hablarle despacio y tranquilizarlo, pero sin lograr éxito alguno. La travesti/trans en cuestión ya se había percatado de mi presencia y hasta me hizo una seña con la mano, indicando que esperara para luego poder hablar con ella.

En ese momento, decidí acercarme a ellos y mi presencia fue, entonces, imposible de evitar. Me entrometí en un conflicto ajeno y, como el muchacho estaba muy agresivo, me dijo: "Básicamente, raja de acá". En consecuencia, tuve una pelea con él: unos empujones, gritos, cosas que suelen ocurrir entre los varones en el contexto de la sociabilidad nocturna. Esa noche, la pelea provocó que cuatro patovicas se acercaran a nosotros y nos dijeran que nos teníamos que ir. La discusión fue subiendo de nivel y continuó incluso fuera del boliche, hasta que un policía nos dijo que cada uno se fuera por un lugar distinto porque, de lo contrario, íbamos a terminar en la comisaría. Respecto de un balance reflexivo, consideré, en principio, que había sido una instancia negativa y pensé que, ante tales obstáculos, existían posibilidades de que la investigación no se realizara. Esta intervención en el trabajo de campo fue premeditada, es decir, sabía que el aproximarme en esa interacción podía generar conflictos y hasta el momento no había logrado resultados, en términos de poder avanzar en la realización de entrevistas. Claro está que el desenlace fue inesperado y que mis intenciones como investigador consistían en tener mayor relevancia dentro del espacio y así poder vincularme con las migrantes que pretendía estudiar.

Los vínculos sexoafectivos que las travestis/trans construyen con varones cisgéneros fueron analizados por otras investigaciones y, pudo observarse que tienen diferentes características, en algunos casos prevalece la reciprocidad y los afectos mientras que en otros predomina el control y las agresiones. Desde mi experiencia de campo, puedo afirmar que en el caso de los varones que se vinculan con estas personas se constituye una masculinidad dual. Dicho de otra manera, se trata de masculinidades hegemónicas en tensión, debido a que constituyen vínculos con personas que han construido una identidad de género por fuera 
de la hetero-cis-normatividad, pero que reivindican valores ligados al control de sus parejas y legitiman sus posiciones ejerciendo la violencia, tal como fue planteado por Kulick (1998).

En estos espacios, pude observar lo que Viveros Vigoya et al. (2001) denominan quebradores, es decir, varones cuya subjetividad posee una supuesta capacidad para conquistar un importante número de mujeres y, en este caso, travestis/trans. De este modo, se evidencia la fragilidad y la necesaria impostura de la masculinidad hegemónica, ya que, en las prácticas de seducción, la conquista de los cuerpos y subjetividades de ellas resulta un factor de confirmación de la virilidad que puede derivar en enfrentamientos con otros varones (Perez Ripossio 2020).

La semana posterior al episodio violento, volví a Amerik y, en la admisión, me solicitaron el DNI, algo poco frecuente debido a los criterios flexibles del lugar con respecto al ingreso. Me sentía bastante envalentonado por el hecho de haber logrado superar la admisión, a pesar del antecedente de disturbio. En la recorrida de Amerik, después de unas horas, volví a dar con la misma travesti/trans de la semana anterior. Me acerqué, la saludé y comenzamos a conversar. A ella le resultaba increíble que todo el conflicto de la semana anterior hubiera sido para solicitarle una entrevista. Además, afirmó que de todas las solicitudes que había escuchado en su vida esa le parecía una de las más extrañas, haciendo hincapié sobre todo en el contexto.

Mariela (nombre alterado) fue la primera entrevistada. Esa noche en Amerik, le solicité su WhatsApp y luego me comuniqué en la semana para concretar esa instancia. Además, logré que otras cinco migrantes travestis/trans me facilitaran sus números, aclarando siempre cuáles eran mis intenciones, dado que este espacio se veía interceptado por dinámicas de índole afectiva. Había gente que me hablaba; de hecho, una pareja heterosexual (varón y mujer cisgénero) y una travesti/trans nativa que eran habitués del lugar me preguntaron qué había ocurrido la semana anterior en relación con la discusión y con el disturbio que había acontecido, con lo cual pude percibir que era una subjetividad que era conocida en el ambiente, debido al revuelo que había ocasionado.

El caso de Mariela permite conceptualizar con mayor profundidad la situación de las travestis/trans sudamericanas que residen en el AMBA. Siendo una travesti colombiana que había llegado al país hacia unos 4 años, expresaba algunos elementos comunes de los proyectos migratorios de otras entrevistadas. Ella constituyó una cadena migratoria mediante un varón cisgénero que conoció mientras que él vacacionaba en Colombia y luego de un tiempo de relación a distancia migró mediante un pasaje que le envió su futuro esposo. Mariela vivió durante 2 años con él y luego de separarse debió ejercer la prostitución teniendo 25 años. Para ella era necesario alejarse de su familia para poder expresar socialmente su identidad de género. En Colombia, se presentaba durante el día con una performatividad propia de un varón cisgénero y por la noche, en espacios destinados a la sociabilidad nocturna, experimentaba otra identidad de género. Usaba prendas femeninas, zapatos de tacón y se maquillaba. Esta dualidad identitaria suele expresarse entre las migrantes debido a las dificultades que implica el expresarse en el espacio público y 
principalmente durante el día. En consecuencia, la migración representa un punto de partida necesario para alejarse de las familias y de los entornos experimentando el anonimato que proporcionan las lejanas grandes urbes.

Volviendo a la cuestión de mi inserción en el trabajo de campo, dado que la mayoría de las personas que asisten a estos lugares se conocen, algunos ya sabían quién era y lo que había ocurrido. Con el tiempo pude constatar que, para las travestis/trans, representaba a un hombre que estaba dispuesto a pelear y eso era algo valorable para ellas. Lejos de generar reactividad, permitió empatizar con la mayoría de las potenciales entrevistadas. Esta situación de violencia derivó, aparentemente, en una violencia epistémica que permitió comenzar a construir conocimiento en esas circunstancias. Las características del universo de estudio influían en la naturalización de la violencia y hasta cierto punto la legitimaban. Esta reflexión fue producto de que, en otras instancias, ellas mencionaron lo acontecido y hasta me felicitaron, afirmando que defender mi posición en el lugar era lo correcto. Con el tiempo, pude percibir la importancia de la violencia en los vínculos que entablan, ya sea con pares, clientes o maridos. La violencia interviene en diferentes momentos de las trayectorias biográficas de las entrevistadas y las conductas que implican la reafirmación de posiciones son observadas como valiosas y legítimas.

Podría afirmarse que Mariela, además de ser entrevistada, ocupó el lugar de portera y fue una colaboradora respecto de cómo organizar la investigación en instancias posteriores. De alguna manera, en las etnografías e investigaciones cualitativas, suele estar presente este suceso que genera un cambio en las condiciones de trabajo. Por eso, resultan importantes los sucesos y vivencias etnográficas ocurridas durante el trabajo de campo.

Mariela fue un actor clave en esta investigación. Ella permitió que conociera diversos códigos que atraviesan la vida social travesti/trans y culturales, sobre todo, de la colombianidad, aunque también de la peruanidad y de la idiosincrasia brasileña, porque algunas de sus amigas pertenecían a esas nacionalidades. Luego de entrevistar a Mariela, procedí a pedirle los contactos de sus amistades para poder entrevistarlas e ir armando un muestreo por bola de nieve. Esta instancia no se concretó, porque algunos de esos teléfonos no los tenía o consideraba que debía pedirles permiso de manera personal. En resumen, me propuso que podía ir a Amerik con ella y con sus amigos/as. En el lugar, podría presentarme a las personas que conocía, que no eran pocas, y la mayoría cumplían los requisitos para ser incorporadas a la muestra.

Luego de unos fines de semana, para las travestis/trans de Amerik, ya era "Tito el bambino". Tal apodo se debía a mi supuesto parecido con "Tito el bambino”, reguetonero pionero colombiano. Dado que tal apodo representaba una suerte de halago, bromeaba con eso y hasta me presentaba bajo ese rótulo cuando conversaba con otras travestis/trans. En este espacio recibía comentarios positivos, piropos provocando que la muestra se acrecentara semana a semana. Este aspecto se consideró relevante porque tal apodo representaba un indicador de prestigio en ese ámbito y eso repercutía de manera positiva en el trabajo de campo porque mi subjetividad se posicionaba de manera favorable. También es importante 
destacar que para ese entonces tenía 28 años y poseía un desarrollo físico y estético que en los espacios de sociabilidad nocturna suele valorarse. Dicho de otra manera, mi apariencia física incidió en el trabajo de campo porque mis características se amoldaban a las exigencias de esos espacios.

Toda esta situación suponía una dualidad en cuanto al acceso al campo: por un lado, había un cerco en las organizaciones políticas que no me permitía acceder y, por el otro, en el venue gay, las personas estaban dispuestas a colaborar con la investigación y el trato era muy cordial. Esta dualidad y disparidad en el acceso pudo suplirse en instancias posteriores, ya que, se logró acceder a algunas organizaciones activistas, pero, hasta ese momento, tal escisión era nítida.

Estas consideraciones no deben dejar de lado el hecho de que mi posición en el espacio social era privilegiada, ya que soy un varón de clase media, heterosexual, cisgénero y nativo. Esto me posicionaba en el lugar del polo dominante. En palabras de Harding, "la clase, la raza, la cultura, las presuposiciones en tomo al género, las creencias y los comportamientos de la investigadora, o del investigador mismo, deben colocarse dentro del marco de la pintura que ella o él desean pintar" (1998, p. 7). En definitiva, es imposible de soslayar ese punto de vista privilegiado que respondió a condiciones objetivas que influyeron en mis maneras de proceder durante el trabajo de campo, teniendo mayores libertades y ventajas, en relación con otras subjetividades. En otras palabras, que pudiera construir contactos con relativa facilidad ilustraba que las características de mi persona se moldeaban al espacio y esto favorecía interacciones con las migrantes.

\section{El cuerpo sexuado del investigador en el campo}

En algunas oportunidades tuve conflictos con varones que estaban en el espacio, pero lejos de preocuparme por eso, sabía que de esa instancia solo podía salir fortalecido, siempre y cuando evitara que me expulsaran nuevamente de ese ámbito, por lo que también descubrí técnicas para esquivar tensiones sin provocar que el desenlace implicara tener que abandonar el lugar. De esta manera, procuraba hablar con todas las travestis/trans que fueran migrantes, incluso si se encontraban acompañadas de amigos o maridos. Mis códigos se regían por el criterio de descripción densa y saturación teórica y, para ello, era necesario hacer contacto con diferentes personas y entrevistar a un importante número de migrantes. Los códigos de las entrevistadas, en cambio, se regían por criterios que evaluaban y ponderaban a los varones según su valentía. Poco a poco fui conociendo diferentes aspectos que les molestaban, siendo la debilidad uno de los rasgos de personalidad que más rechazaban. Por eso, es posible suponer que, para ellas, el haber resuelto una adversidad mediante una pelea les haya parecido algo para revalorizar.

Los fundamentos de mi labor en Amerik eran discutidos por algunos/as de los habitués, ya que no creían que estuviera ahí solo para realizar entrevistas. Afirmaban que me encontraba en el lugar para otros fines, factor que, tal como la plantea Braz (2010), suele estar presente en espacios con algunas similitudes respecto de este, como los clubes de sexo. 
Pero a mí no me molestaba lo que dijeran. Lo único molesto era que me ignorasen y, como eso no ocurría, continuaba concentrado en avanzar en el trabajo de campo. La versión definitiva, que crearon los participantes de Amerik, establecía que yo era un periodista amigo de Mariela que quería saber cómo era el trato de las travestis/trans migrantes en el país receptor. Esa idea se fue generalizando hasta tal punto que mi subjetividad no desentonaba y era parte del espacio con total naturalidad.

Es difícil ser parte de un ámbito y no jugar de acuerdo con las reglas establecidas por este. Más allá de los discursos sobre la buena onda que reinan en estos lugares, se ha podido constatar que determinadas subjetividades poseen un valor relativo más elevado que otras. En los boliches gays (y en los heterosexuales), si bien hay diferencias y matices, se aprueban determinadas apariencias físicas. De este modo, tono de voz, gestos, posturas e indumentaria, habilidad para comunicarse y otros indicadores de capital erótico (Hakim, 2012) son fundamentales para poder generar interacciones sólidas. En ese sentido, mi presencia no desentonaba con las exigencias que suelen presentarse en los venues gays y percibía que ocupaba un lugar privilegiado; en definitiva, apreciaba que era posible generar conversaciones e interacciones de diferente índole.

Las características subjetivas de los investigadores y las investigadoras influyen en la construcción de los datos. Autores como Braz (2010) y Díaz Benítez (2013) han reflexionado sobre el papel del investigador en espacios en los que la seducción y los vínculos afectivos se encuentran presentes. Este factor es imposible de soslayar y los autores mencionan la importancia de problematizar la supuesta asexualidad del etnógrafo y ser reflexivos sobre los efectos que el investigador puede generar en los sujetos que estudia cuando se realiza trabajo de campo. De este modo, Cutuli (2013) sostiene que las etnografías clásicas latinoamericanas se han visto atravesadas por la cuestión del lugar que asume el cuerpo sexuado del investigador en el campo. Y este cuerpo es un cuerpo sexuado en el que median observaciones recíprocas, por lo que sus efectos son insoslayables.

Con fundamento en Díaz Benítez (2013), realizar un trabajo etnográfico en la noche implica generar interacciones en espacios atravesados por vínculos afectivos que ubican al investigador en un lugar de cuestionamiento y sospecha permanente, en donde la propia sexualidad entra en un espacio de cuestionamiento. En efecto, Braz (2010) reflexiona sobre su experiencia de campo en una investigación en clubes destinados a la socialización y al sexo entre varones homosexuales. Refiere a las etnografías tabúes o impropias, en las que la sospecha sobre las intenciones del investigador en el campo es moneda corriente, lo que posibilita y, a la vez, obstaculiza la construcción de conocimiento. Al respecto, Kulick y Wilson (1995) consideran que la sexualidad de los investigadores es una dimensión para tener en cuenta, ya que condiciona las interpretaciones teóricas que se realizan sobre los datos construidos por la investigación.

A partir del "destape" que supuso el conocimiento de los diarios de Malinowski, Kulick y Wilson (1995) entienden que la oscuridad y los silencios sobre la sexualidad de los investigadores en el campo son parte de los tabúes etnográficos. Entonces, ser reflexivo de 
los efectos que pueden ocasionarse en espacios en donde la seducción representa el eje de las interacciones es pertinente y debe asumirse como una de las controversias éticas. En mí caso, intenté aplicar un filtro ético para contextualizar las conversaciones en los venues a partir de comunicarles a las personas partícipes que me encontraba desarrollando una investigación, factor que desataba sospechas y cuestionamientos por la veracidad de mis dichos. Además, la sexualización que recaía sobre mi persona impactaba en mi subjetividad, porque al ser un cuerpo potencialmente deseable entendía que las interacciones que entablaba podían provocar malos entendidos. Y esos malos entendidos, podían ser responsabilidad tanto de las partícipes como del propio investigador.

En otros trabajos, el antropólogo Kulick (1998), en una etnografía sobre la población travesti/trans realizada en el Brasil y respecto del trabajo llevado a cabo por Silva, afirmaba:

Se presentó ante las travestis como un cliente potencial, un papel que claramente debió haber tenido profundas consecuencias para los tipos de relaciones que desarrolló con las travestis. Si bien mi punto no es contradecir a las mujeres que me advirtieron que las travestis nunca me aceptarían, y proponer que, de hecho, solo los hombres homosexuales realmente pueden hacer trabajo de campo entre travestis (eso no tendría sentido, teniendo en cuenta el valor de los estudios publicados por Prieur, Oliveira y Silva), sugiero que, como hombre abiertamente gay, alguien que se percibe como un viado me posicionó de una manera que pudo haber facilitado el acceso a discusiones y confidencias que podrían no haber sido otorgadas tan fácilmente a las mujeres ( $\mathrm{y}$ ciertamente no a clientes potenciales) (Kulick 1998: 16). ${ }^{4}$

De este fragmento pueden hacerse dos reflexiones. En primer lugar, para el antropólogo nórdico, el único papel que podría tener un investigador en los espacios en los que se ejerce la prostitución/trabajo sexual es el del cliente. Lo segundo, que una persona gay puede ser un confidente y estar en mejores condiciones para desarrollar investigaciones de este tipo. Más allá de que no desprecia los aportes de investigadores/as heterosexuales (asumiendo que Silva y Oliveira lo eran), lo fundamental radica es que la subjetividad del investigador impacta en el modo de construir conocimiento. El antropólogo Silva había accedido a sus informantes presentándose como cliente y esto implicó cuestionamientos

\footnotetext{
${ }^{4}$ Traducción libre. Texto original: Presented himself to travestis as a potential client-a role that clearly must have had profound consequences for the types of relationships he developed with individual travestis. While my point is not to spitefully turn the tables on the women who warned me that travestis would never accept me, and propose that in fact only gay men can really do fieldwork among travestis (that would be meaningless, considering the value of the studies published by Prieur, Oliveira, and Silva), I do suggest that as an openly gay man, someone perceived to be a viado like them, I was positioned by travestis in a way that may have facilitated access to discussions and confidences that might not have been granted as easily to women (and certainly not to potential clients) (p. 16).
} 
éticos y sobre la calidad de los datos construidos. La capacidad de establecer rapport con las entrevistadas cuando median pagos se construye de manera deteriorada porque la figura del cliente dista de la del investigador y se corre el riesgo de que los usos del tiempo queden asociados con la lógica del ejercicio de la prostitución/trabajo sexual.

Hay un acuerdo generalizado y tácito en el ámbito académico que establece que los varones cisgénero suelen tener condiciones de acceso más favorables respecto de las mujeres cisgénero. Esta afirmación puede matizarse, debido a que lo decisivo es el capital social con el que cuentan los investigadores y las investigadoras, sobre todo, a la hora de hacer contacto con el activismo. La necesidad de acceder a casos en espacios destinados para fines distintos a la realización de la investigación evidenció el cerco institucional existente para determinadas subjetividades que no se encuentran vinculadas a la militancia política feminista o transfeminista. A las condiciones de acceso de esta investigación, además del cerco institucional, se le puede adicionar un cerco ético porque debían evitarse formas de proceder que resultaran engañosas o poco claras, por lo que fue necesario asumir un papel reflexivo.

Mi inserción en la sociabilidad nocturna -en la que Mariela fue una protagonista clave, debido a que me posibilitó la participación en otras instancias- fue fundamental para mejorar la calidad de los datos producidos. Ella organizaba reuniones en su departamento y convocaba amistades, incluso a parte del personal de Amerik. El acceder a contextos íntimos permitió la escritura del diario de campo y avanzar en el análisis de los proyectos migratorios de las entrevistadas. En esas instancias, las participantes, en su mayoría, eran migrantes travestis/trans sudamericanas, lo que permitía que hiciera contacto para entrevistarlas $a$ posteriori, o bien, registrara aspectos que referían a los proyectos migratorios de manera indirecta, empleando la observación participante.

Si bien todo parecía marchar bien, en un determinado momento, tuve que comenzar a recurrir a otros venues porque las personas que asistían a Amerik empezaban a repetirse y las opciones de entrevistas se acotaban, ya que había entrevistado prácticamente a todas las habitués del lugar que eran migrantes travestis/trans sudamericanas. Por eso, estos procedimientos fueron aplicados en una multiplicidad de venues a los que asistía el universo de estudio.

El conocimiento de estos espacios implicó constituir un capital social necesario para poder acceder a otras entrevistadas. La reflexividad es uno de los elementos imposibles de soslayar en donde resulta necesario entender los efectos que el investigador genera en el campo y cómo ese contexto lo modifica e impacta también en él relacionalmente (Guber 2019). Hacer trabajo de campo en estos escenarios no es sinónimo de "ir a boliches"; en todo caso, estos espacios, que pueden denominarse venues, configuran interacciones que involucran la subjetividad del investigador e impactan en las interacciones que allí se generan. Un elemento que se consideró desde un primer momento fue dejar en claro a los participantes de estos espacios con los que interactuaba que mi presencia se debía a la realización de una investigación y, por eso, me interesaba conversar con ellos. 
El trabajo etnográfico realizado no se limitó a la sociabilidad nocturna en estos espacios, también se realizó en uno de los barrios de la Ciudad Autónoma de Buenos Aires.

\section{Constitución nocturna}

El barrio de Constitución, ubicado en el centro-sur de la Ciudad de Buenos Aires, representó un enclave fundamental para esta investigación. Este espacio sintetiza buena parte del significado de las migraciones travesti/trans en el AMBA, con lo cual fue necesario realizar trabajo de campo en este espacio. El interrogante principal que retomé en esta instancia, en función de los debates proporcionados por las etnografías clásicas ya mencionadas fue: ¿es posible ser parte de un escenario en donde se ejerce la prostitución/trabajo sexual sin ser un cliente o un enemigo? La respuesta se despejó con la práctica y eso involucraba definir un papel como investigador en un espacio que abarcaba diferentes complejidades.

Durante varias noches del verano del 2018, realicé trabajo de campo en el barrio de Constitución, caracterizado por ser un centro comercial con medios de transporte con importante circulación diurna. Es un barrio polifacético en la que hay hoteles destinados al ejercicio de la prostitución/trabajo sexual y hoteles/pensiones familiares, aunque también se ejerce dicha actividad. En el lugar, se encuentra un restaurante dominicano denominado Caribaní. Se trata de un sitio en el que siempre hay música a gran volumen y una fuerte iluminación, donde se conjuga un restaurante de ambiente cultural con un ambiente propio de una discoteca y hay importante presencia de migrantes dominicanos y migrantes travestis/trans sudamericanas.

Las travestis/trans, durante el tiempo en el que ejercen la prostitución/trabajo sexual en esa zona, se reúnen en la calle, conversan un rato y se dirigen a este restaurante/bar, en el contexto de un descanso destinado a la sociabilidad y el encuentro. En las aceras de Constitución ellas deambulan a la espera de clientes que pueden aproximarse en automóviles, o bien, como transeúntes que luego de la jornada laboral buscan relacionarse con fines recreativos o poder realizar fantasías sexuales ajenas a las normas. Sobre la prostitución denominada callejera Fernández (2004) y Suárez (2006), en Argentina, aportaron que esta se realiza por diversos motivos siendo la necesidad de acceder a recursos económicos determinante. Pues la mayoría de las migrantes ve deteriorada sus condiciones de vida al expresar socialmente sus identidades de género, sin poseer otras alternativas.

Este espacio involucra, para las migrantes, diferentes interacciones sociales que no se limitan al ejercicio de esta actividad. Constitución es un nudo de relaciones sociales en el que ellas se vinculan también con frecuentadores, novios o maridos. Además, se establecen lazos que oscilan entre el compañerismo, el enfrentamiento o la indiferencia. Las migrantes se acompañan cuando algún cliente se comporta con agresividad, utilizando el escándalo (Cutuli 2015) como un método de defensa, intercambian información sobre la situación del barrio, sobre el accionar violento de las fuerzas de seguridad y comparten sociabilidades en bares del barrio en los que narran sucesos de sus cotidianeidades. No obstante, desarrollan 
comportamientos ligados al enfrentamiento entre sí como consecuencia de disputas de control espacial en el ejercicio de esta actividad. En otras ocasiones, debido a rispideces anteriores, desarrollan actitudes de indiferencia lo que supone no intervenir en situaciones de riesgo para sus pares.

Teniendo en cuenta esta dinámica, fui parte de la escena y asistí a este espacio con el fin de conseguir otras entrevistas y enriquecer el material empírico construido hasta el momento. Caribaní comenzó a ser el venue de Constitución, espacio en el que realicé algunas entrevistas y logré comunicarme con ellas mediante conversaciones de relevancia teórica, posicionándome como una de las subjetividades conocidas del barrio.

La sociabilidad nocturna en el barrio de Constitución no se limita a Caribaní, ya que en la zona pueden encontrarse otros bares con una dinámica similar. En esas noches, conocí a Carolina, una mujer cisgénero que vivía en una pensión del barrio. Ejercía la prostitución/trabajo sexual de manera esporádica y vendía estupefacientes. A ella la entrevisté porque me dijo que conocía diferentes aspectos en detalle sobre las biografías de las migrantes travesti/trans. La entrevista se realizó al lado de Caribaní, sentados en la puerta de una casa abandonada. Carolina siempre estaba preparada; circulaba con navajas y afirmaba que el perímetro cercano a la pensión en la que vivía estaba bajo su control. Me presentaba a migrantes travestis/trans y les explicaba que era un sociólogo interesado en conocer aspectos de sus biografías. En el barrio de Constitución, la noche asume una tensión permanente que se expresa en el ejercicio de la prostitución/trabajo sexual que se conjuga con la venta de drogas (cocaína), hurtos y atracos con armas blancas, sumado a peleas entre travestis/trans, con la policía y entre los trapitos y fisuras ${ }^{5}$. Estas últimas se tratan de categorías nativas que evidencian situaciones de conflicto, violencia, fuerte presencia policial y marginalidad.

Una de las travestis/trans que rondaba el espacio ejerciendo la prostitución/trabajo sexual y a quién denomino Anabela, era peruana y su trayectoria biográfica poseía elementos de una "biografía modelo" (Bataillon y Juárez 2008). Tenía solo 19 años y había estado detenida en un penal juvenil por venta de estupefacientes. Según relataba, toda su familia se dedicaba a esa actividad. El padre no quería tratarla por su condición de género, debido a que afirmaba que era una vergüenza y que dejaba mal posicionada a su familia. En Constitución, Anabela, no se esforzaba en que consiguiera casos, pero de vez en cuando me presentaba a otras personas y yo podía comentarles cuál era mi labor.

La historia de Anabela no distaba demasiado de otras biografías. Más allá de las características hostiles de los entornos de origen, esas hostilidades continúan luego de que los itinerarios se concretan. Pues el AMBA les ofrece un marco legislativo inclusivo, pero también transitan violencias discriminaciones, violencias y vulnerabilidades. Esto se traduce en cuestiones concretas. Por ejemplo, en relación con las violencias, describen diferentes

\footnotetext{
${ }^{5}$ Término que suelen usar las entrevistadas para referirse a varones de bajos ingresos que se desplazan por las zonas en las que se ejerce la prostitución/trabajo sexual y que pueden resultar peligrosos porque les roban o las golpean cuando ellas se niegan a conseguirles estupefacientes.
} 
situaciones de maltrato policial, agresiones sexuales de parte de los clientes y embestidas de pares que intentan controlar los espacios en los que se ejerce la prostitución. En cuanto a las discriminaciones, estas se expresan tanto por la identidad de género como por la condición migratoria. Es decir, ser una travesti o mujer trans sudamericana representa una experiencia única y distintiva porque en los itinerarios que realizan la identidad de género y la condición de migrantes se articulan y producen nuevas vulnerabilidades que se expresan en la restricción de derechos. Son personas atravesadas por características que la sociedad receptora rechaza y controla como consecuencia de la transgresión de normas que llevan a cabo.

Durante una de las noches en las que estuve en el barrio de Constitución con Anabela, debido a que íbamos a dirigirnos a una fiesta en Constitución, tres policías, dos varones y una mujer nos detuvieron y nos dijeron que nos pusiéramos contra la pared. Uno de los policías me preguntó: “¿Vos sabes que no es una mujer?”. Me dijeron que iban a ir hasta mi auto, que lo conocían porque lo habían visto por la zona varias veces. Uno de los policías me dijo: "Si llegás a tener falopa, te meto preso". También me preguntaron si llevaba armas y realizaron una requisa minuciosa del vehículo con linternas, abriendo las puertas e, incluso, el baúl. Además, me requisaron a mí y a ella, como si fuéramos presuntos delincuentes que actuábamos en conjunto. No obstante, como ninguno de los dos llevaba algo que pudiera complicarnos, tuvieron que retirarse diciendo que la noche en Constitución era muy complicada y se trataba de un procedimiento de rutina. Este es un ejemplo de lo expuesto anteriormente, dado que las fuerzas de seguridad ejercen control sobre las migrantes y, este caso, quienes las acompañan. Este tipo de requisas que pueden incluir tratos vejatorios fue algo narrado por las entrevistadas en diferentes oportunidades, incluso hubo relatos de agresiones sexuales.

Tal vivencia etnográfica ilustra las condiciones que experimentan las migrantes travestis/trans, que, como relataron en las entrevistas, con frecuencia son sometidas a requisas vejatorias y maltratos policiales en las que se evidencia la reproducción de discursos ideológicos hetero-cis-normativos y diferentes tipos de violencias. Las calles del barrio de Constitución en donde ellas ejercen la prostitución/trabajo sexual nuclean violencias y consumo de drogas y mi inmersión como investigador vivenció algunos de esos aspectos.

En el barrio de Constitución, podía hacerse trabajo de campo con relativa facilidad, tanto durante el día como durante la noche. En más de una oportunidad, aplicaba un método de aproximación directo, es decir, caminando las calles del barrio hablaba con algunas migrantes travestis/trans que ejercían la prostitución/trabajo sexual y se encontraban aburridas por la escasa demanda de clientes. Como la crisis económica también las afectaba, sobre todo a fin de mes, con solo saludarlas y conversar un poco bastaba para luego ir a un bar cercano y realizar las entrevistas. Para ese entonces, era conocido por la mayoría de las travestis/trans (nativas y migrantes), por los dueños de los bares y por la policía. Mi subjetividad era parte del entorno y se tomaba con total naturalidad. 


\section{Conclusiones}

En este artículo realicé un aporte a las problemáticas vinculadas con las migraciones de personas travestis/trans en clave teórico-metodológica. La presentación del trabajo de campo describió los diversos momentos que atravesó la investigación, los obstáculos y también los vectores que resultaron claves para poder acceder a la información de relevancia. Algunos aspectos ligados a la reflexividad se plantearon en relación con la dimensión del lugar del cuerpo sexuado del investigador en el campo. La descripción de los escenarios y las vivencias etnográficas demuestran que, en el trabajo de campo, cuya duración fue de casi dos años, las entrevistas realizadas y la observación participante permitieron construir datos acordes con la máxima variabilidad y densidad posible.

La caracterización de los escenarios del trabajo de campo permite determinar de qué maneras se accedieron a los casos que compusieron la muestra. Las características del investigador, como la etnia, la clase social, el género, la orientación sexual y el capital social son condiciones que influyen en el acceso al campo. Además, la dimensión del cuerpo sexuado y factores como la violencia deben tenerse en cuenta, puesto que se presentaron en diversas instancias. Otra característica fundamental y que fue mencionada en el cuerpo del artículo se vincula con la apariencia física del investigador. En los espacios ligados a la sociabilidad nocturna la juventud, la indumentaria a la moda y el desarrollo corporal son aspectos con implicancias concretas que posibilitan generar interacciones y acceder a las personas estudiadas. Estas características propias pueden favorecer el trabajo de campo, pero también es necesario ser reflexivo sobre los efectos que pueden producirse en las personas estudiadas.

Al retomar los interrogantes planteados en la introducción considero que el realizar trabajo de campo en espacios atravesados por la sociabilidad nocturna implica redefinir criterios de acuerdo con las diferentes situaciones que se presentan. Las controversias éticas que ocasionan fueron descriptas en el contexto de la estrategia desplegada con el fin de alcanzar una descripción densa del fenómeno. Un aspecto de importancia fue el desafío metodológico que implicó, ante condiciones desfavorables de acceso, poder haber realizado la investigación incorporando una importante cantidad de casos. De todas maneras, dicha labor no se encontró exenta de contradicciones que podrán ser recapituladas en investigaciones futuras.

\section{Bibliografía}

BATAILLON, Gilles; JUÁREZ, Vania Galindo. 2008. Trabajo del antropólogo y trabajo de los testigos, la Mosquitia 1982-2007. Estudios sociológicos, vol. 26, n.78: 509-555.

BERKINS, Lohana. (2003). Un itinerario político del travestismo. In: MAFFÍA, Diana. (comp.). Sexualidades Migrantes. Género y Transgenero. Buenos Aires: Scarlett Press. Pp.127-137. 
BLÁZQUEZ, Gustavo. 2012. Masculinidades cool. Estudios: Centro de Estudios Avanzados, vol. 27: 45-57.

BLÁZQUEZ, Gustavo; LIARTE TILOCA, Agustin. 2018. De salidas y derivas. Anthropological Groove y "la noche" como espacio etnográfico. Íconos. Revista de Ciencias Sociales, 60: 193-216 DOI 10.17141/ iconos.60.2018.2630.

BRAZ, Camilo Albuquerque. 2010. “Mas agora confessa...”: Notas sobre clubes de sexo masculinos. Sexualidad, Salud y Sociedad, vol. 4, n. 4: 127-156.

CEREZO, Alison; MORALES, Alejandro; QUINTERO, Danielle; ROTHMAN, Stephanie. 2014. Trans migrations: Exploring life at the intersection of transgender identity and immigration. Psychology of Sexual Orientation and Gender Diversity, vol. 1, n.2: 170-180. DOI $10.1037 /$ sgd0000031.

CUTULI, María Soledad. 2013. Etnografiando travestis: preguntas, tensiones y aprendizajes sobre el" estar ahí". Sexualidad, Salud y Sociedad, vol. 13: 99-112. DOI 10.1590/S198464872013000100006.

CUTULI, María Soledad. 2015. Entre el escándalo y el trabajo digno. Etnografia de la trama social del activismo travesti en Buenos Aires. (Tesis doctoral). Buenos Aires: Universidad de Buenos Aires. Disponible en: http://repositorio.filo.uba.ar/handle/filodigital/4610.

DÍAZ BENÍTEZ, María Elvira. 2013. Algunos comentarios sobre prácticas sexuales y sus desafíos etnográficos. Apuntes de Investigación del CECyP, n. 23: 13-33.

FERNÁNDEZ, Josefina. (2004): Cuerpos desobedientes. Travestismo e identidad de género. Buenos Aires: Edhasa.

GÓMEZ, Gregorio Rodríguez; FLORES, Javier Gil; JIMÉNEZ, Eduardo García. 1999. Metodología de la investigación cualitativa. Málaga: Aljibe.

FLICK, Uwe. 2007. Introducción a la investigación cualitativa. Madrid: Ediciones Morata.

GEERTZ, Clifford. 1987. La interpretación de las culturas (pp. 19-40). Barcelona: Gedisa.

GUERRA, Verônica Alcântara. (2020). Circulação, afetos e migração: notas para uma análise antropológica de mulheres trans em terras indígenas da Paraíba. Contemporânea Revista de Sociologia da UFSCar, vol. 10, n.1: 101-123. DOI: 10.4322/2316-1329.130

GUBER, Rosana. 2004. El salvaje metropolitano: reconstrucción del conocimiento social en el trabajo de campo. Buenos Aires: Paidós.

GUBER, Rosana. 2019. La etnografia: método, campo y reflexividad. Buenos Aires: Siglo XXI.

HAKIM, Catharine. 2012. El capital erótico: el arte de fascinar a los demás. Barcelona: Debate.

HARAW AY, Donna. 1995. Ciencia, cyborgs y mujeres: la reinvención de la naturaleza. Madrid: Cátedra.

HARDING, Sandra. 1998. ¿Existe un método feminista? In: BARTRA, Eli. (Comp). Debates en torno a una metodología feminista. México, D. F.: Universidad Autónoma Metropolitana. pp.9-34

HERNÁNDEZ SAMPIERI, Roberto; COLLADO, Carlos Fernández; LUCIO, María del Pilar Baptista. 2010. Metodología de la Investigación. México: Mac graw Hill. 
KULICK, Don; WILLSON, Margaret (Eds.). 1995. Taboo: sex, identity, and erotic subjectivity in anthropological fieldwork. Psychology Press.

KULICK, Don. 1997. The gender of Brazilian transgendered prostitutes. American Anthropologist, vol.99, n.3: 574-585. DOI: 10.1525/aa.1997.99.3.574.

KULICK, Don. (1998). Travesti: Sex, gender, and culture among Brazilian transgendered prostitutes. Chicago: University of Chicago Press.

PADILLA, Mark; RODRÍGUEZ-MADERA, Sheilla; VARAS-DÍAZ, Nelson; RAMOSPIBERNUS, Alixida. 2016. Trans-migrations: border-crossing and the politics of body modification among Puerto Rican transgender women. International Journal of Sexual Health, vol. 28, n.4: 261-277.

PÉREZ RIPOSSIO, Ramiro Nicolas. 2020. Devenir "macho alpha”: performances de seducción heterosexual en una escuela de coaching de la Ciudad de Buenos Aires. Revista Interdisciplinaria de Estudios de Género de El Colegio De México, vol.6, n.1: 1-33. DOI 10.24201/reg.v6i0.554

PERLONGHER, Néstor. (1993). La prostitución masculina. Buenos Aires: Ediciones de la Urraca.

RIEZNIK, Martin; TABASCHEK, Mike. (2013). El juego de la seducción. Buenos Aires: Dibuks.

STANG, María Fernanda. 2013. Aflojando el corsé. Los estudios sobre migraciones internacionales y génerps en la Argentina. En Cathalifaud (Coord.). XXIX Congreso de la Asociación Latinoamericana de Sociología. Santiago de Chile, Chile.

STRAUSS, Anselm; CORBIN, Juliet. 2002. Bases de la investigación cualitativa: técnicas y procedimientos para desarrollar la teoría fundamentada. Antioquia: Universidad de Antioquia.

TAYLOR, S. J; BOGDAN, R. 1987. Introducción a los métodos cualitativos de investigación (Vol. 1). Barcelona: Paidós.

VARTABEDIAN, Jlieta. (2012). Geografia travesti: cuerpos, sexualidad y migraciones de travestis brasileñas (Rio de Janeiro-Barcelona). (Tesis de doctorado). Barcelona: Universitat de Barcelona. Recuperado de: http://hdl.handle.net/2445/35232.

\section{sobre el autor}

\section{Ramiro Nicolas Pérez Ripossio}

Doctor en Sociología, magister en investigación social y licenciado en Sociología.

Autoría: No aplicable

Financiación: No aplicable.

Fecha de recibimiento: 08/01/2021

Fecha de aceptación: 27/07/2021 